\title{
Peritoneal Dialysis Fluid
}

National Cancer Institute

\section{Source}

National Cancer Institute. Peritoneal Dialysis Fluid. NCI Thesaurus. Code C154852.

The dialysis fluid which is collected from the peritoneal space and captures, for discard or analysis, the excess water and waste from the blood stream through diffusion and ultrafiltration. $(\mathrm{NCl})$ 